\title{
Clinical diagnosis of achalasia: How reliable is the barium x-ray?
}

\author{
I El-Takli MD FRCPC ${ }^{1}$, P O'Brien MB ChB FRCPC ${ }^{2}$, WG Paterson MD FRCPC ${ }^{1}$
}

I El-Takli, P O'Brien, WG Paterson. Clinical diagnosis of achalasia: How reliable is the barium $\mathrm{x}$-ray? Can J Gastroenterol 2006;20(5):335-337.

Manometry is considered to be the gold standard for the diagnosis of achalasia. However, many physicians believe that contrast radiography, classically showing esophageal dilation with bird-beak narrowing of the gastroesophageal junction, is also accurate in either diagnosing or excluding the disorder. The aim of the current study was to determine the accuracy of barium $\mathrm{x}$-ray in the diagnosis of achalasia. The radiological diagnosis of all patients manometrically diagnosed with achalasia (using conventional criteria) between January 1994 and June 1998 were reviewed. A total of 51 cases of achalasia were identified. Thirteen patients were excluded because they either did not have contrast radiography before a manometric diagnosis or had their $\mathrm{x}$-rays performed more than six months previously. Of the remaining 38 patients, achalasia was stated as a diagnostic possibility in the radiologists report in only $22(58 \%)$ of those patients. Achalasia was not considered in the remaining 16 patients: two were reported as normal, four as having stenosis/narrowing in distal esophagus, two as having presbyesophagus, one as having mild gastroesophageal reflux and seven as having nonspecific dysmotility. To determine the reason for the diagnostic failure of the barium $\mathrm{x}$-ray, an expert gastrointestinal radiologist reviewed 12 of the nondiagnostic x-rays in a blinded fashion, interspersed with 10 randomly selected esophageal-contrast radiographs from control subjects to avoid bias. Of these initially nondiagnostic $\mathrm{x}$-rays in achalasia patients, typical radiological features of achalasia were deemed to be present in $50 \%$. The present study indicates that contrast radiography lacks sensitivity in the diagnosis of achalasia. This is not only due to radiologist oversight but also because of the absence of the characteristic radiological features in many cases. This reinforces the important role of esophageal manometry in patients with persistent nonstructural dysphagia.

\section{Le diagnostic clinique d'achalasie: Quelle est la fiabilité du repas baryté?}

La manométrie est considérée comme le diagnostic de référence de l'achalasie. Cependant, de nombreux médecins sont d'avis que la radiographie de contraste, qui révèle une dilatation classique de l'œsophage avec rétrécissement en bec d'oiseau de la jonction gastro-œsophagienne, est également précise pour diagnostiquer ou exclure ce trouble. La présente étude visait à déterminer la précision du repas baryté dans le diagnostic d'achalasie. Le diagnostic radiologique de tous les patients atteints d'une achalasie diagnostiquée par manométrie (au moyen des critères classiques) entre janvier 1994 et juin 1998 a été évalué. Un total de 51 cas d'achalasie a été repéré. Treize patients ont été exclus parce qu'ils n'avaient pas subi de radiographie de contraste avant le diagnostic par manométrie ou que leur radiographie de contraste avait été exécutée plus de six mois auparavant. Le rapport du radiologiste citait l'achalasie parmi les possibilités diagnostiques chez seulement $22(58 \%)$ des 38 patients restants. L'achalasie n'a pas été envisagée chez les 16 autres patients : on a considéré que deux étaient normaux et que quatre souffraient de sténose ou de rétrécissement de l'œsophage distal, deux, de presbyœsophage, un, de reflux gastro-œsophagien léger et sept, de dysmotilité non spécifique. Pour déterminer la raison de l'échec diagnostique du repas baryté, un radiologiste spécialisé en gastroentérologie a analysé 12 des rayons $\mathrm{X}$ non diagnostiques en aveugle, mêlés à 10 radiographies œesophagiennes de contraste provenant de sujets témoins choisis aléatoirement, afin d'éviter les biais. Les caractéristiques radiologiques classiques d'achalasie ont été constatées dans $50 \%$ des rayons $\mathrm{X}$ non diagnostiques de patients atteints d'achalasie. D'après la présente étude, la radiographie de contraste n'est pas assez sensible pour diagnostiquer l'achalasie. Cette non-sensibilité s'explique non seulement par une omission de la part du radiologiste, mais également par l'absence de caractéristiques radiologiques de nombreux cas. Ce constat renforce le rôle important de la manométrie œsophagienne chez les patients atteints d'une dysphagie fonctionnelle persistante.

Key Words: Contrast radiography; Dysphagia; Esophageal motor disorder; Esophagus; Manometry

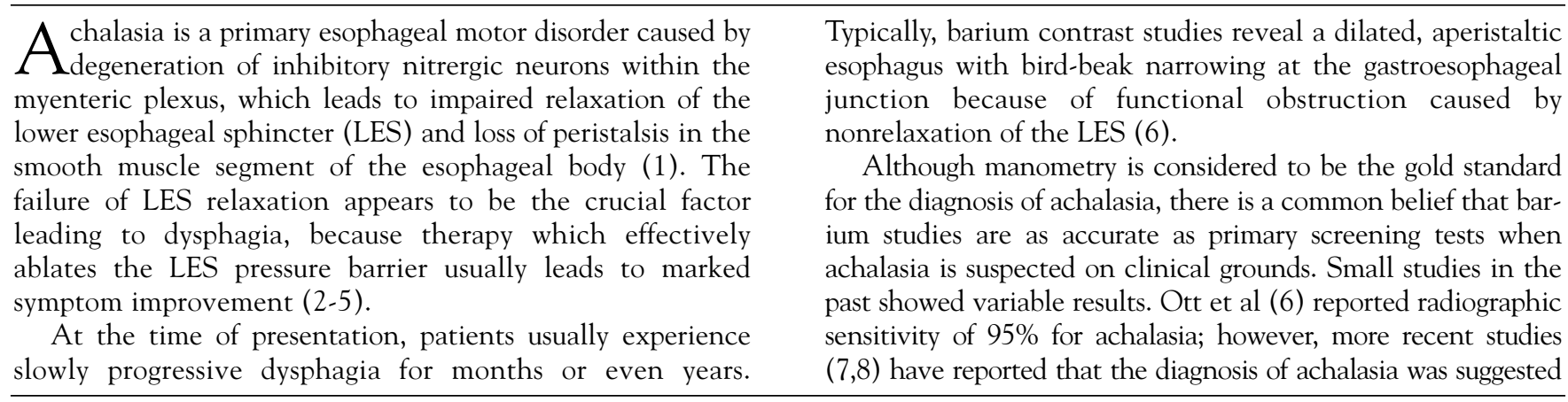

Gastrointestinal Diseases Research Unit and Departments of ${ }^{1}$ Medicine and ${ }^{2}$ Radiology, Queens University, Kingston, Ontario

Correspondence: Dr William G Paterson, Hotel Dieu Hospital, 166 Brock Street, Kingston, Ontario, K7L 5G2.

Telephone 613-544-3400 ext 2292, fax 613-544-3114, e-mail patersow@hdh.kari.net

Received for publication November 14, 2005. Accepted January 24, 2006 


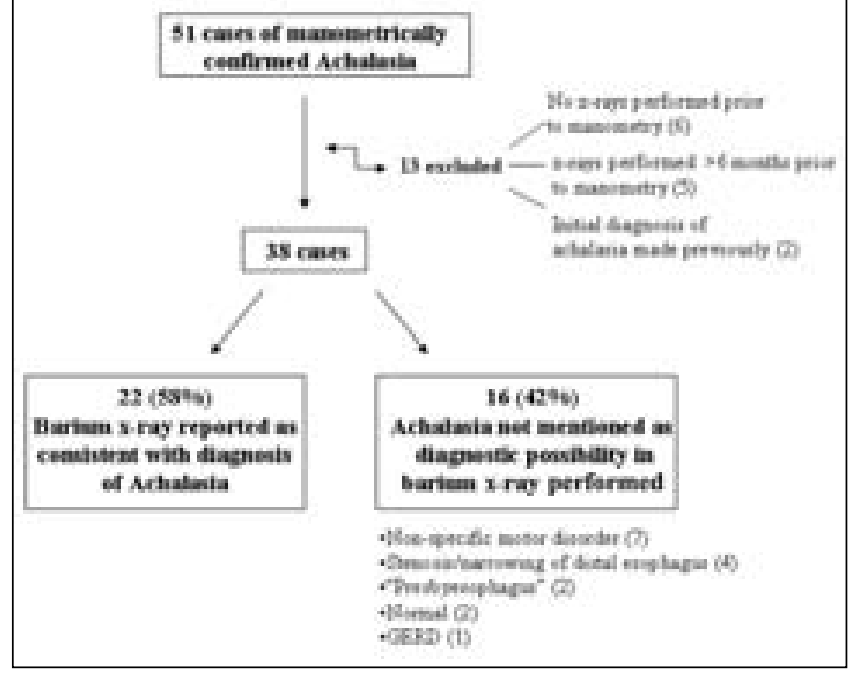

Figure 1) Summary of data on sensitivity of barium swallow $x$-ray in the diagnosis of achalasia. GERD Gastroesophageal reflux disease

by videofluoroscopy in less than two-thirds of patients who had manometrically proven achalasia. The reasons for this apparent lack of sensitivity were not clear.

The aim of the present study was to evaluate the diagnostic accuracy of barium $\mathrm{x}$-rays in the diagnosis of achalasia and to determine the reasons for its diagnostic failure.

\section{PATIENTS AND METHODS}

All patients manometrically diagnosed with achalasia at Hotel Dieu Hospital (Kingston, Ontario) between January 1994 and December 1998 were identified. Standard manometric criteria were used to make the diagnosis (9). Patients all had the typical manometric features of achalasia, including complete aperistalsis and either absent or markedly impaired (less than 50\%) swallowinduced LES relaxation. Detailed chart review was performed to exclude cases of secondary achalasia and to identify reports of esophageal barium contrast studies. If patients were referred in from other institutions, the respective radiology departments were contacted to determine if barium contrast studies had been performed before manometry. Patients were excluded if they had no barium $\mathrm{x}$-ray before manometry or if their barium $\mathrm{x}$-ray was performed more than six months before the manometric study. In addition, patients who had their initial diagnosis before January 1994 and were returning for follow-up manometry were excluded. Original radiological reports were reviewed and classified as to whether the diagnosis of achalasia was considered by the reporting radiologist.

To determine the reason for the diagnostic failure, an expert gastrointestinal radiologist reviewed the nondiagnostic $\mathrm{x}$-rays in a blinded fashion interspersed with 10 randomly selected esophageal-contrast radiographs from control subjects who underwent barium swallow for reasons other than dysphagia. The control radiographs had been interpreted as either being normal or showing minor reflux only. Three criteria were used by our radiologist to diagnose achalasia:

- dilation of the esophagus;

- bird-beak narrowing of the gastroesophageal junction; and

- evidence of stasis.

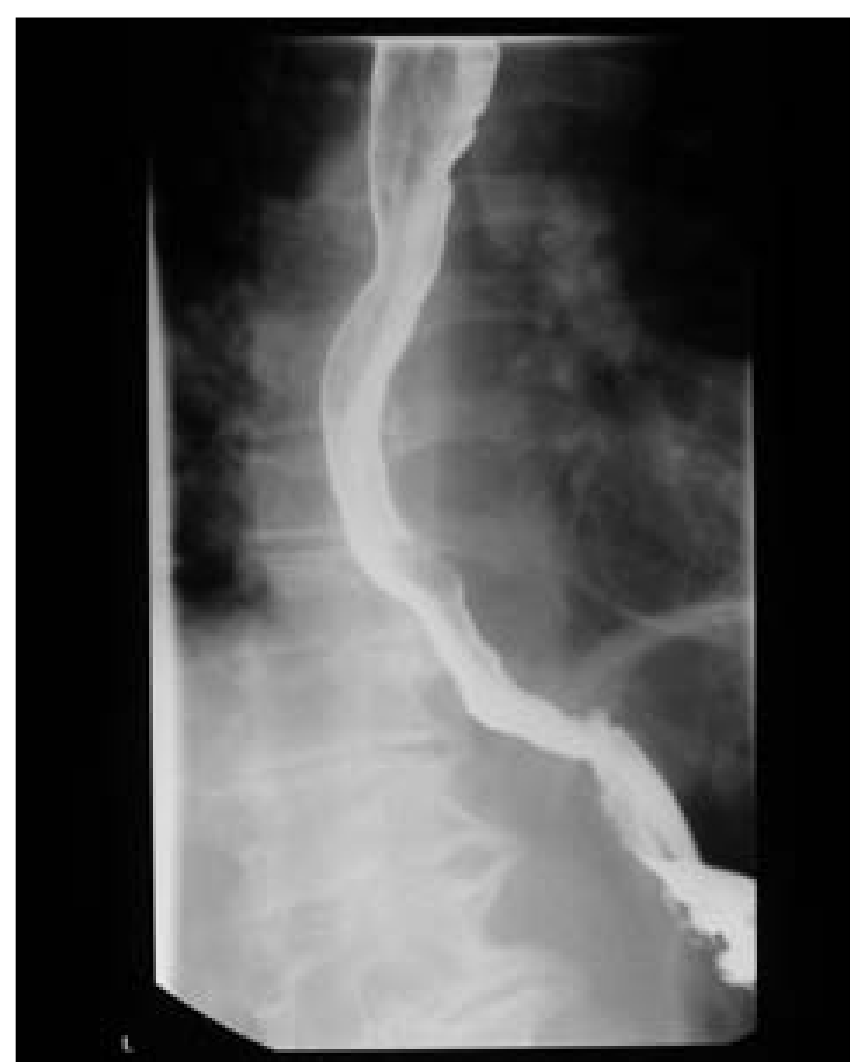

Figure 2) Example of nondiagnostic barium swallow x-ray in a patient with manometrically confirmed idiopathic achalasia

If all three criteria were present, the $\mathrm{x}$-ray was interpreted as diagnostic of achalasia, if two of the three criteria were present, the $\mathrm{x}$-ray was interpreted as possible achalasia and if one or none of the criteria were present, the $\mathrm{x}$-ray was interpreted as nondiagnostic of achalasia.

\section{RESULTS}

Of the 51 patients who had manometric diagnosis of achalasia during the five-year period, five were excluded because their $\mathrm{x}$-rays were performed more than six months before the manometry, two because they were initially diagnosed before 1994 and six because no $\mathrm{x}$-rays were performed before manometry. Of the remaining 38 patients, barium swallow or cine esophagram was suggestive of achalasia (as per the radiologist report) in 22 patients $(58 \%)$ and nondiagnostic in 16 patients $(42 \%)$ (Figure 1). Seven of the nondiagnostic $\mathrm{x}$-rays were interpreted as nonspecific motility disorder, four as stenosis/narrowing in distal esophagus, two as presbyesophagus, two as normal and one as gastroesophageal reflux disease.

Twelve of the 16 nondiagnostic $\mathrm{x}$-rays were available to the gastrointestinal radiologist. This was performed to identify the reasons for the diagnostic failure, whether it was secondary to radiologist oversight versus lack of typical radiological features. Of the 12 initially nondiagnostic x-rays, five $(41.7 \%)$ had all three of the predetermined criteria for achalasia, two $(16.6 \%)$ had two of the three criteria and five (41.7\%) had one or none of the criteria for achalasia. The $\mathrm{x}$-rays that had one or none criteria for achalasia were all interpreted as showing a nonspecific esophageal motor disorder (Figure 2). 


\section{DISCUSSION}

The present study demonstrates that radiography missed the diagnosis of achalasia in $42 \%$ of the patients. The reason for missing the diagnosis varied. In five of 12 of the missed cases in which barium $\mathrm{x}$-rays were available for review, it was clearly secondary to radiologist oversight in that all three of the classic criteria were present. However, in most of the remaining cases, the classic radiographic features of achalasia were absent.

The early diagnosis of achalasia has major clinical significance because delays in the diagnosis results in delays in the institution of effective therapy, with resulting morbidity and impaired quality of life. Videofluoroscopy clearly carries a much better chance of detecting motility disorders, including achalasia, than static films. Our radiologist was only able to retrospectively review spot films, but the radiologist who originally performed the study presumably would have viewed the fluoroscopic images. It could also be argued that we underestimated the sensitivity of contrast-radiography, because any radiographic evidence of esophageal dysmotility in a patient with dysphagia would trigger a request for manometry to firmly establish the diagnosis. However, we do not believe this approach is widely practiced in Canada, particularly given the limited access to esophageal manometry. In addition, nonspecific esophageal motor abnormalities are common in asymptomatic individuals (10) despite the very low incidence of achalasia.

In a series of 33 patients with manometrically confirmed achalasia reported by Howard et al (7), barium swallow $\mathrm{x}$-ray was considered consistent with or suggestive of

\section{REFERENCES}

1. Paterson WG. Etiology and pathogenesis of achalasia. Gastrointest Endosc Clin N Am 2001;11:249-66.

2. Spiess AE, Kahrilas PJ. Treating achalasia: From whalebone to laparoscope. JAMA 1998;280:638-42.

3. Csendes A, Braghetto I, Henriquez A, Cortes C. Late results of prospective randomized study comparing forceful dilatation and oesophagomyotomy in patients with achalasia. Gut 1989;30:299-304.

4. Gelfond M, Rozen P, Gilat T. Isosorbide dinitrate and nifedipine treatment of achalasia: A clinical, manometric and radionuclide evaluation. Gastroenterology 1982;83:963-9.

5. Pasricha PJ, Rai R, Ravich WJ, Hendrix TR, Kalloo AN. Botulinum toxin for achalasia: Long term outcome and predictors of outcome. Gastroenterology 1996;110:1410-5. achalasia in $45 \%$ and $21 \%$ of patients, respectively; in the remainder, achalasia was not considered. A more recent study by Schima et al (8) showed similar results in that the diagnosis of achalasia was suggested using barium swallow videofluoroscopy in only $58 \%$ of the cases that were diagnosed manometrically. Of the remainder, $34 \%$ were reported to show nonspecific motor disorders while $8 \%$ were reported as normal. These results are comparable with the results of the present study. The results of the study by Ott et al (6) showing a sensitivity of $95 \%$ for detecting achalasia by radiographic studies has never been reproduced in subsequent studies.

The current study did not address the issue of specificity of the barium swallow $\mathrm{x}$-ray in the diagnosis of achalasia when the classic $\mathrm{x}$-ray features were present. To date, there are no published studies addressing this issue; however, we have seen rare cases where the barium swallow was thought to have the characteristic features of achalasia, yet manometric criteria for the diagnosis were absent.

\section{CONCLUSION}

Contrast radiography lacks sensitivity in the diagnosis of achalasia. This can be partially rectified by increasing awareness among radiologists regarding the diagnostic features of the disease. However, it is clear that classic $\mathrm{x}$-ray features may not be present in some patients. Thus, to avoid misdiagnosing patients with a readily treatable disease, manometry should be performed in all patients with persisting esophageal-type dysphagia but negative endoscopy and radiological examinations.

6. Ott DJ, Richter JE, Chen YM, Wu WC, Gelfand DW, Castell DO. Esophageal radiography and manometry: Correlation in 172 patients with dysphagia. Am J Roentgenol 1987;149:307-11.

7. Howard PJ, Maher L, Pryde A, Cameron EW, Heading RC. Five year prospective study of the incidence, clinical features, and diagnosis of achalasia in Edinburgh. Gut 1992;33:1011-5.

8. Schima W, Ryan JM, Harisinghani M, et al. Radiographic detection of achalasia: Diagnostic accuracy of videofluoroscopy. Clin Radiol 1998;53:372-5.

9. Paterson WG, Marciano-D'Amore DA, Beck IT, DaCosta LR. Esophageal manometry with provocative testing in patients with noncardiac angina-like chest pain. Can J Gastroenterol 1991;5:51-7.

10. Ekberg $\mathrm{O}$, Feinberg MJ. Altered swallowing function in elderly patients without dysphagia: Radiologic findings in 56 cases. Am J Roentgenol 1991;156:1181-4. 


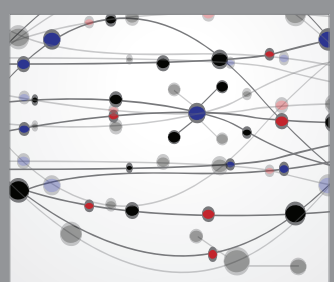

The Scientific World Journal
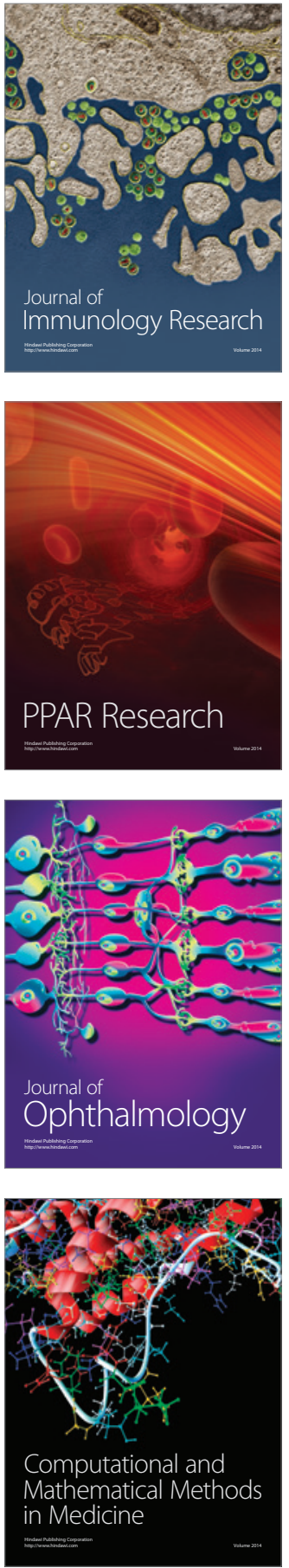

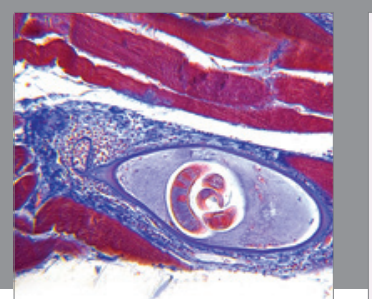

Gastroenterology Research and Practice

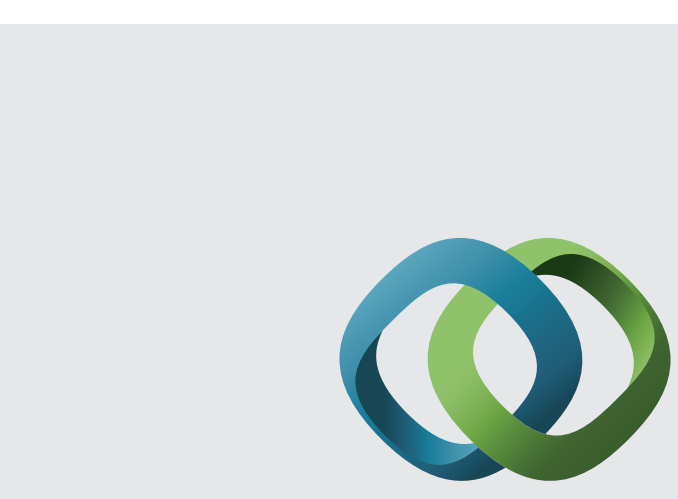

\section{Hindawi}

Submit your manuscripts at

http://www.hindawi.com
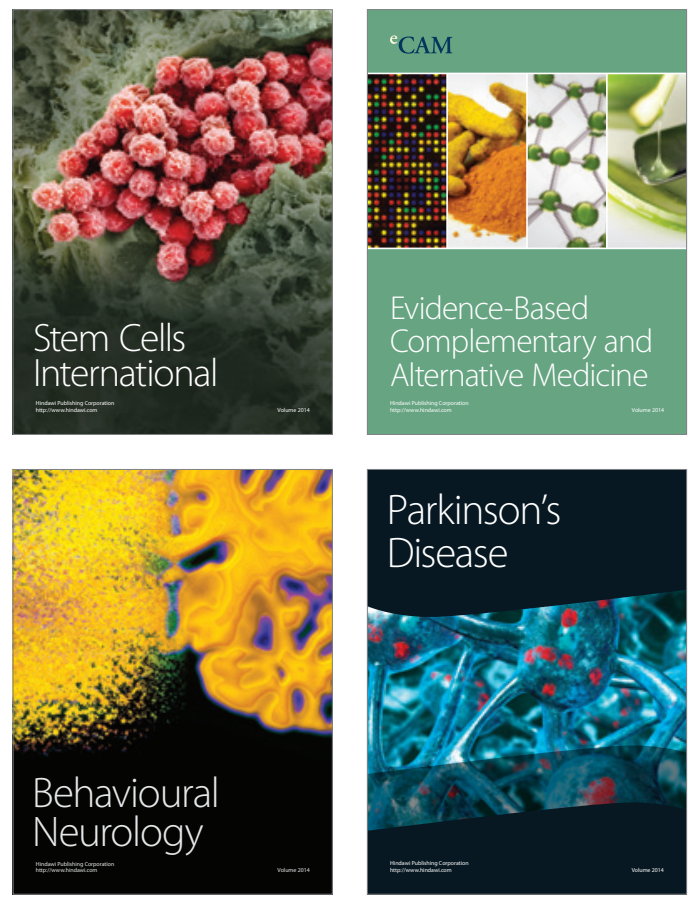
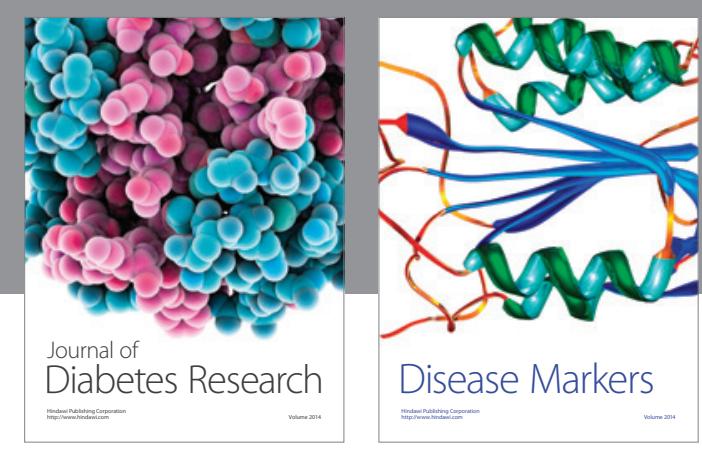

Disease Markers
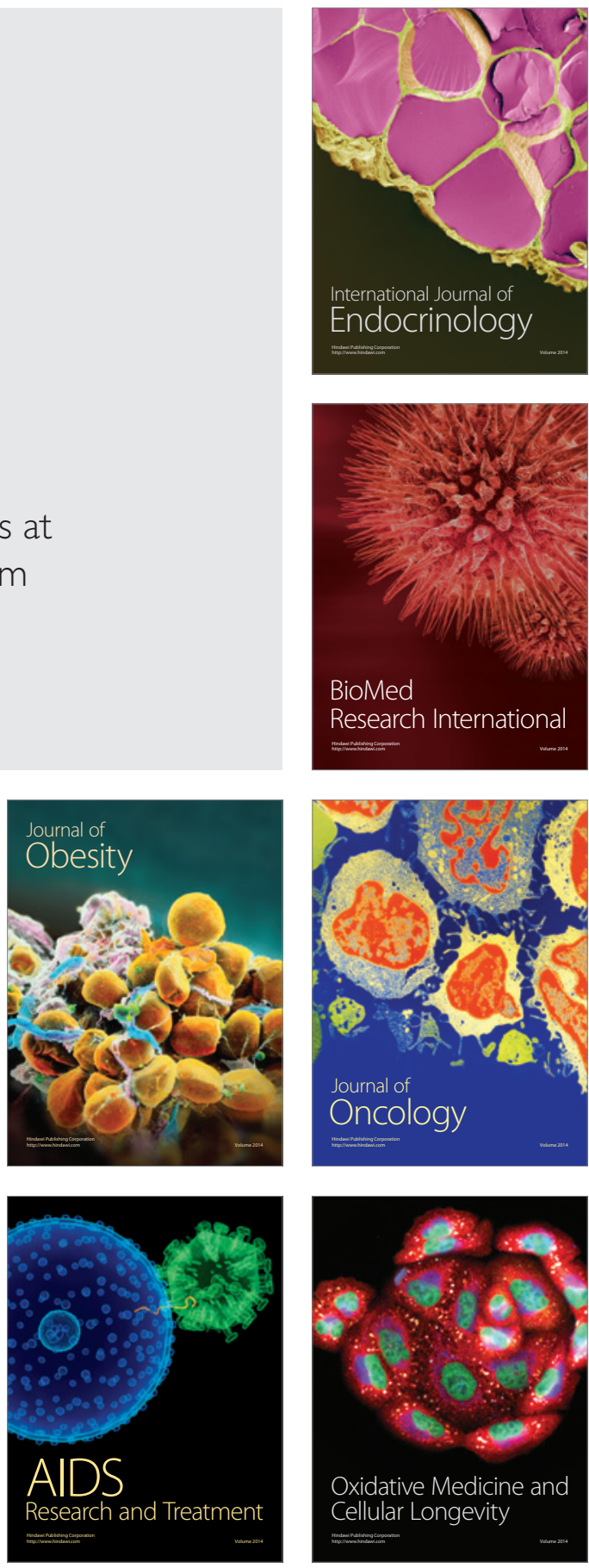